\title{
MIGRACIÓN Y DEVOCIONES TRANSFRONTERIZAS
}

\author{
PATRICIA ARIAS* \\ JORGE DURAND**
}

RESUMEN: El artículo describe y analiza el surgimiento, desde fines del siglo XIX, de devociones inéditas en la frontera norte de México y el sur de Estados Unidos, para indagar acerca de la construcción social de una nueva espacialidad religiosa y votiva en esa territorialidad emergente, fuera y alejada de los espacios e imágenes religiosos tradicionales de México. Esa territorialidad emergente, elaborada a partir de los nuevos tránsitos, estancias y permanencias en un contexto menos cargado de tradiciones acarreó y permitió un profundo cambio religioso, una nueva ritualización y simbolización del espacio. El artículo sugiere que en la construcción y difusión de las devociones emergentes de la frontera tuvo mucho que ver un elemento inédito: la aparición y popularización de nuevas tecnologías y los nuevos usos de las tecnologías de comunicación.

PALABRAS CLAVE: Religiosidad popular, cambio religioso, nuevas tecnologías, migración, tradiciones.

ABSTRACT: This article analyzes and describes the development of new religious devotions in the Mexican northern border and the southern United States since the late 19th century. It examines the social construction of a new religious and votive space in an emerging territoriality outside traditional Mexican religious spaces and images. This emerging territoriality, based on new types of transit, permanence, and settlement in a context less weighed down with tradition led to a profound religious change and a new ritualization and symbolization of space. This article suggests that the development and dissemination of these border devotions is closely related to a previously absent element: the development and popularization of new technologies and the new uses given to communication technologies.

KEYWORDS: Popular religiosity, religious change, new technologies, migration, traditions.

* Profesora-Investigadora Departamento de Estudios Socio-Urbanos, Universidad de Guadalajara parias@prodigymovil.com

** Es Profesor-Investigador Titular del Departamento de Estudios sobre los Movimientos Sociales (DESMoS) de la Universidad Autónoma de Guadalajara e-mail jdurand@megared.net.mx 

n las últimas tres décadas del siglo XIX en la frontera norte comenzaron a aparecer un sinfín de devociones populares inéditas en la tradición religiosa mexicana: el culto a personas contemporáneas que fueron revestidas de santidad y sujetas de intensa devoción, al menos en su momento. La secuencia comenzó, quizá, con don Pedrito Jaramillo, jalisciense que llegó a Olmos, Texas donde sanaba a la gente de los ranchos cercanos, además de salir él mismo a atender pacientes (Malagamba, 1992). Y, concluyó, al parecer, en 1938, con la muerte natural del Niño Fidencio y el fusilamiento de Juan Soldado. Los que lograron mayor arraigo, perdurabilidad y difusión fueron cuatro personajes que se hicieron famosos en los estados norteños de Baja California, Chihuahua, Coahuila, Nuevo León, Sinaloa, Sonora, Tamaulipas, Arizona y el sur de Texas en Estados Unidos: Teresa de Urrea, más conocida como la Niña o la Santa de Cabora; José de Jesús Fidencio Cíntora Constantino, al que todos llamaban El Niño Fidencio; Jesús Malverde, cuyo nombre habría sido Jesús Juárez Maso y Juan Soldado, que se llamaba Juan Castillo Morales. Devociones transfronterizas que surgieron y se popularizaron en el siglo XIX y perduraron, algunas, a lo largo del siglo $\mathrm{xx}$.

El artículo describe y analiza el surgimiento de esas devociones en la frontera norte para indagar acerca de la construcción social de una nueva espacialidad religiosa y votiva en esa territorialidad emergente elaborada a partir de nuevos tránsitos, estancias, permanencias; así como en lo que esa construcción representa en términos de cambio religioso, de nueva ritualización y simbolización del espacio. El artículo sugiere que en la construcción y difusión de las devociones emergentes de la frontera tuvo mucho que ver, además, un elemento inédito: la aparición y popularización de nuevas tecnologías y nuevos usos de las tecnologías de comunicación.

\section{LA FRONTERA, PERMANENCIAS Y NOVEDADES}

La guerra México-Estados Unidos de 1846-1848, dice José Manuel Valenzuela, dio lugar al surgimiento de «nuevos héroes y tradiciones» en ambos lados de la frontera. Del lado norteamericano, predominaron los héroes bélicos asociados a la victoria. Del lado mexicano, héroes populares y luchadores sociales «que proyectaban los deseos de resistencia y desquite» así como bandoleros sociales y santos populares que prosperaron frente a la «indefensión social y la miseria cotidiana» (1992: 14).

Y es que sin duda, entre 1850 y 1880, se intensificó, como nunca antes, la llegada, el paso, la salida, la permanencia de gente, atraída y expulsada por diversos motivos que fueron entretejiendo una trama social nueva y compleja a ambos lados de la nueva línea fronteriza entre México y Estados Unidos. No sólo eso. Los impulsos que catapultaban los nuevos tránsitos estaban muy asociados a enor- 
mes transiciones culturales y movimientos sociales que habían convertido a la gente en testigo y víctima de acontecimientos, lejanos y cercanos, que trastocaban, de manera irremediable, el rumbo y ritmo de sus vidas.

Por una parte, por ese amplio espacio se movían, desde siempre, diferentes grupos indígenas, sobre todo los que pasaron a ser norteamericanos, en especial, los apaches. Después de la guerra, los indígenas, muchos de ellos belicosos, que se movían con facilidad entre ambos lados de la frontera, empezaron a ser sistemáticamente perseguidos y brutalmente diezmados por los ejércitos de uno y otro país (Anaya, 1992; Diario de Jalisco, 5 de julio de 1890). Gracias a convenios específicos las tropas de México y de Estados Unidos podían cruzar la frontera en "persecución de indios hostiles» (El Correo de Jalisco, 18 de junio de 1896). Así, entre el asentamiento pacífico, la resistencia y el bandidaje la frontera se volvió cada vez más difusa. La prensa mexicana daba cuenta tanto del interés de indígenas norteamericanos por comprar tierra en Sonora y Baja California, como de cuadrillas, también de indígenas de Estados Unidos, que cometían «robos y asaltos en la frontera mexicana» (La Libertad, 20 de octubre de 1898; Diario de Jalisco, 14 de marzo de 1890).

A los mayos, en el lado mexicano, tampoco les iba mucho mejor como trabajadores de las haciendas. A partir de 1890, los indígenas iniciaron una serie de revueltas que engancharon a una variedad de imágenes religiosas poco difundidas por la iglesia oficial y también a «santos vivos» (Domecq, 1992).

Al mismo tiempo, antiguos pobladores mexicanos de la región, sobre todo en Texas, fueron despojados de sus tierras por propietarios y compañías norteamericanas; situación que los convirtió en peones empobrecidos y endeudados (Malagamba, 1992). La misma autora señala que el «carácter y tipo de organización (de las propiedades) adquirió cada vez más parecido al de la Hacienda en México» (1992: 67).

Las nuevas situaciones fronterizas y también la secuela revolucionaria dieron lugar a personajes nuevos en la región, como Catarino Garza, que después de haber cobrado alguna fama -como la de haber combatido a Porfirio Díaz- se convertían en bandoleros que "resucitaban» en diferentes lugares, dedicados a actividades delictivas que pasaban a formar parte de la tradición oral (La Libertad, 14 de marzo de 1897).

La turbulencia y ambigüedad de las tensiones y luchas llevaban con facilidad a "movimientos sediciosos», pero también a la injusticia y a más violencia (Domecq, 1992). En 1901, la matanza de un sheriff a manos de dos abigeos mexicanos en un pueblo de Texas, desencadenó la movilización de otro sheriff y ochocientos hombres que, además de torturar a un «labrador», un muchacho mexicano de 16 años, se dedicaron a cometer «infinidad de atrocidades con indefensos y pacíficos mexicanos que no tienen más culpa que ser hijos de México» (La Libertad, 4 de julio de 1901). Entre una cosa y otra, la Ley Fuga se aplicaba con generosidad y a las cárceles de Estados Unidos fueron a parar un sinfín de mexicanos 
a los que se trataba particularmente mal, decía la prensa (Diario de Jalisco, 3 de mayo de 1890; El Correo de Jalisco, 12 de marzo de 1896).

Por otra parte, la frontera no fue inmune a la ola de migraciones hacia Estados Unidos y hacia América Latina que se desató desde 1880. Allí, como en tantas partes, empezaron a llegar inmigrantes de diversas nacionalidades atraídos por el empleo en los ferrocarriles y minas; por la posibilidad de colonizar tierras (Diario de Jalisco, 15 de abril de 1890). Fue el caso de los chinos, que llegaron sobre todo a Sinaloa y Sonora, donde parecería haberse desatado la competencia entre trabajadores chinos y mexicanos (La Libertad, 30 de octubre de 1898; 16 de abril de 1899). A la prensa de la época, le preocupaba que la inmigración china perjudicara a "nuestra clase proletaria» y corrompiera «más las costumbres de nuestro pueblo» (Diario de Jalisco, 15 de abril de 1890). La prensa mexicana se mostró abiertamente racista, prejuiciosa y difamadora con los inmigrantes de origen chino.

Hubo también, al parecer, otras inmigraciones, como la de «familias alemanas» a Nuevo León y, más tarde, Tamaulipas, atraídas por la posibilidad de dedicarse «al cultivo de la fructífera planta del algodón» (Diario de Jalisco, 21 de febrero de 1890). Para la prensa nacional la inmigración alemana, a diferencia de la china, era iBienvenida!, porque los alemanes eran, «por lo general, sobrios, trabajadores y respetuosos» (La Libertad, 19 de noviembre de 1899).

El encuentro con la diversidad alcanzó también el ámbito religioso. Además de los extranjeros que pertenecían a distintas iglesias protestantes hubo mexicanos que se convirtieron a esas creencias, sobre todo al pentecostalismo y comenzaron, incluso, a realizar actividades proselitistas en el norte de México (Gaxiola, 1994). La Iglesia Apostólica de México comenzó a difundirse desde Los Ángeles, Cal., hacia pequeñas poblaciones de Sonora, Chihuahua, Nuevo León, Coahuila (Gaxiola, 1994). En la región de La Laguna, hacia 1918, dice Gaxiola «estaban presentes las iglesias bautista, metodista y presbiteriana» (1994: 158). En 1900 en los estados de la frontera norte, aunque con poca población, se ubicaba el $27 \%$ de los que declararon ser protestantes, proporción que se incrementó al 32\% en 1910 (Hernández, 1999). El cambio religioso había comenzado.

Además de recibir y definir las relaciones con diversos flujos de inmigrantes y creyentes, las poblaciones de la frontera comenzaban a perfilar sus vocaciones. Un ejemplo notable fue Tijuana, recientísimo y pequeñísimo asentamiento que aceptó la llegada de actividades que el puritanismo y las leyes norteamericanas buscaban expulsar de su territorio: bares, cantinas, licorerías, cervecerías, casas de juego, prostitución, zonas de tolerancia, el famoso hipódromo de Agua Caliente; todas, dedicados a atraer turistas, artistas y mafiosos de Estados Unidos que eran atendidos por empobrecidos y azorados trabajadores mexicanos (Valenzuela, 1992; Vanderwood, 2004). En tanto persistía la incomunicación con el resto del país, así como entre las poblaciones mexicanas de la frontera, las pequeñas poblaciones de México tendían a definirse en función de las relaciones que establecían con Estados Unidos. 
Un último elemento. La ampliación de las líneas ferrocarrileras en Estados Unidos y su comunicación con los ferrocarriles de México desde la década de 1880 marcaron el inicio de la migración masiva de trabajadores mexicanos a la frontera norte. La oferta de trabajo en las vías y trenes, promocionada y controlada por los enganchadores, comenzó a llevarse a infinidad de trabajadores mexicanos, sobre todo a los del centro-occidente del país, a estaciones de la frontera donde eran fácilmente reclutados para trabajar en Estados Unidos (Durand y Arias, 2005; La Libertad, 31 de julio de 1902). La historia del coyotaje, desde entonces, empezó a acumular historias de horror (Durand y Arias, 2005).

Hay que añadir que también las catástrofes naturales y sociales impulsaban olas expansivas de emigración al otro lado, en especial, a Texas (Diario de Jalisco, 26 de septiembre de 1890). Las autoridades mexicanas de la frontera y del interior del país se quejaban y denunciaban la salida de connacionales pero poco podían hacer frente a la oferta de trabajo, de mejores salarios, de mayor seguridad en Estados Unidos (Durand y Arias, 2005; Diario de Jalisco, 26 de septiembre de 1890). Hay que decir que los migrantes estaban expuestos a múltiples vejaciones, ataques $y$, desde luego, infinidad de accidentes de trabajo (Durand y Massey, 2001; Diario de Jalisco, 30 de abril de 1890; El Correo de Jalisco, 30 de octubre de 1895).

A principios del siglo xx la inmensa mayoría (96.76\%) de los migrantes mexicanos se ubicaba en siete estados norteamericanos donde abundaban los quehaceres agropecuarios, mineros o había centros ferroviarios de importancia. Más de la mitad se encontraba en poblaciones de Texas (56.53\%), donde se habían ubicado las principales agencias enganchadoras. Con proporciones muy menores de trabajadores mexicanos estaban California (15.22\%), Arizona (13.40\%), Nuevo México (5.42\%), Kansas (3.83\%), Oklahoma (1.20\%) y Colorado (1.16\%) (Durand y Arias, 2005). En principio, se trataba de una migración predominantemente masculina, pero también familiar, que buscaba el retorno a México, pero donde resultaba difícil definir los periodos de estancia, más todavía a raíz de la revolución de 1910 que tuvo en vilo al país y sus sufridos habitantes durante toda la década de 1910-1920. La migración, señala Vanderwood (2004), tendía a debilitar los lazos de la gente con la iglesia y daba pie a nuevas prácticas religiosas.

Los migrantes se encontraban con un espacio físico y social muy diferente de lo que ellos conocían y reconocían: tenían que trabajar en tierras inhóspitas e increíblemente frías; tenían que aprender a desplazarse en ciudades enormes de geografía desconocida, más aún para gente que, en muchísimos casos, no sabía leer ni escribir. El retablo de don Matías Lara, de San Luis Potosí, es buen testimonio de esa angustia. Él, perdido en Chicago en 1918, ciudad que se representa con muchos edificios, caminos y vehículos, le agradece a la Virgen de San Juan de los Lagos el "haber iluminado el camino que buscaba» (Durand y Massey, 2001).

Una sorpresa, entre muchas, para esos campesinos migrantes de raigambre profundamente católica debe haber sido la escasez de iglesias, imágenes y tradi- 
ciones religiosas a las que ellos estaban profundamente vinculados y que en situaciones de alto riesgo, como migrar, trabajar, vivir y sobrevivir en Estados Unidos, les hacían falta. Muchos de ellos, sin duda, mantuvieron la tradición de acudir, a su regreso, a sus santuarios predilectos en México a cumplir las mandas y promesas contraídas por algún favor recibido en Estados Unidos, a veces muchos años después de sucedido, cuando al fin, un día, pudieron regresar a su tierra. Pero no todos. Otros se dedicaron a recrear y resignificar su religiosidad en el nuevo espacio de la frontera.

\section{LA TRADICIÓN HEREDADA}

En general, los migrantes de ese tiempo provenían y compartían una profunda y vigorosa formación religiosa hecha de antiquísimas imágenes asociadas a santuarios y procesiones, originada, en muchos ejemplos, en el «aparicionismo» (Barabás, en prensa). El «aparicionismo», es decir, el surgimiento de una imagen sagrada -muchas veces mariana- en algún lugar fue, durante la conquista y la colonia, una práctica muy socorrida para generar devociones y asentar cultos en México. Así, los intereses de la sociedad y la iglesia coloniales dieron lugar a una geografía religiosa con imágenes y calendarios jerarquizados que iban desde devociones locales hasta grandes cultos nacionales como la Virgen de Guadalupe (Barabás, en prensa).

Esa manera de generar imágenes y devociones fue contrastada y contestada, con base en esos mismos recursos, por grupos sociales emergentes, situación que dio lugar a la aparición, durante el siglo XIX, de nuevos espacios regionales de devoción católica. Durante esa centuria se advierte un proceso intenso e inédito de apropiación, por parte de grupos sociales y regionales emergentes, de los dispositivos creadores de la devoción y de las prácticas votivas que tanto habían servido a la conquista espiritual colonial (Arias, 2004). A las imágenes coloniales se sumaron, durante el siglo XIX, devociones como la del Santo Niño de Atocha, en Fresnillo, Zacatecas y dos Cristos dolientes como el Señor del Saucito en San Luis Potosí y el Señor de la Misericordia en Tepatitlán, en los Altos de Jalisco. Las historias de sus orígenes resuenan conocidas. Casi todo el mundo ha escuchado relatos, muchos de ellos del siglo XIX, que aluden a dos situaciones: en primer lugar, a la aparición de imágenes en sitios y con manifestaciones inesperadas, entre las que destacan las ramas de árbol con forma de cruz que evocaban la imagen de Cristo crucificado.

En segundo lugar, a la férrea voluntad de la imagen por permanecer en un sitio determinado, lo cual ella misma hacía saber a su feligresía pesando mucho para que no la pudieran mover o, en caso de ser trasladada, regresando, sin que se supiera cómo, al lugar de su querencia. En casi todos los casos la devoción a la flamante imagen se acompañó de una auténtica fiebre de visitas, que muy pronto se convirtieron en peregrinaciones, así como de ruegos, demandas y favores que 
se plasmó en la instalación de inacabables y agradecidos exvotos que daban cuenta y reiteraban, a propios y extraños, su calidad milagrosa (Arias, 2004).

De este modo, puede decirse que en el siglo XIX se dio un proceso de redefinición de la espacialidad heredada a la territorialidad creada. Redefinición que puso de manifiesto las nuevas prioridades, los nuevos arreglos sociales e intereses políticos que fueron surgiendo respecto al espacio y que en el ambiente de tensión e inestabilidad políticos no podían expresarse por los cauces tradicionales (Arias, 2004). En ese proceso de ruptura con la espacialidad colonial y de redefinición de territorios significativos, las imágenes y la tradición votiva jugaron un papel central. Poner a las imágenes a decidir donde establecerse, afincarse en un territorio y dotarlas de poderes milagrosos que se manifestaban, de inmediato, en expresiones votivas, era una manera de legitimar y sacralizar el asentamiento de un grupo social para el cual los viejos ámbitos coloniales habían dejado de tener sentido, de responder a los usos -tránsitos, establecimiento, significados- que los pobladores decimonónicos requerían.

Esas maneras de crear nuevas espacialidades y catapultar devociones fueron utilizadas con gran éxito por la gente del campo en el siglo XIX. Aunque difícil, no era imposible. En general, se trataba de poblaciones rurales con tradiciones y recursos, saberes y prácticas más o menos homogéneas, más o menos compartidas en cuanto a las expresiones y las posibilidades de recreación de la experiencia religiosa.

En la frontera norte las situaciones social, política, cultural y religiosa eran desde luego muy diferentes. Allí la iglesia católica tenía escasa fuerza y menor presencia histórica que en el resto de México. El contexto ideológico era también muy distinto. En lo que podía haber coincidencia era en la necesidad de construir expresiones religiosas que les dieran sentido e identidad a los flamantes vecinos en sus nuevos territorios.

\section{LA TRADICIÓN RECREADA}

Entre 1880 y 1940 la frontera vio aparecer y prosperar la devoción a dos tipos de personajes. Por una parte, a personas vivas que se hicieron ampliamente conocidas por su fama de santidad asociada a su capacidad para realizar curaciones «milagrosas». Las noticias de esas curaciones milagrosas corrían por pueblos y ranchos de uno y otro lado de la frontera y mucha gente, hombres y mujeres, se animaba a emprender la travesía para ser sanados, pero también para conocer al santo y visitar el lugar de los hechos, convertido en recinto de peregrinación. Fueron los casos de la Santa de Cabora y el Niño Fidencio, ampliamente conocidos y venerados en vida. Por otra parte, a personajes que, una vez muertos, comenzaron a hacer milagros que convirtieron sus tumbas en lugares de peregrinación y 
devoción. Fueron los casos de Jesús Malverde y Juan Soldado. Ellos ilustran la transición de taumaturgos vivos a transgresores muertos como sujetos de devoción.

Diferentes autores han dado cuenta de la vida, milagros y penurias de esos cuatro personajes: Teresa Urrea, la Santa de Cabora (Domecq, 1990, 1992; Vanderwood, 1998), el Niño Fidencio (Berlanga, 1999; Monsiváis, 1992; Riley, 1996), Jesús Malverde (Lizárraga, 1998), Juan Soldado (Valenzuela, 1992; Vanderwood, 2004). Por lo tanto, no es necesario repetir sus biografías. Más bien, gracias a ellos es posible intentar una comparación y algunas reflexiones. Quizá el de biografía más ambigua, menos evidente sea Jesús Malverde, ya que se duda incluso que haya existido (Lizárraga, 1998). Los otros tres tuvieron, sin duda, vidas reales que han sido documentadas lo mejor posible y son la base de lo que sigue.

La vida de todos ellos estuvo marcada por un hecho nuevo: la movilidad, característica que marca una gran diferencia con la inmovilidad tradicional de gran parte de la población mexicana que empezó a romperse justamente durante el porfiriato y con la construcción de los ferrocarriles. La Santa de Cabora nació en 1873 en un pequeño rancho indígena de Ocorini, en Sinaloa, se movió a Cabora, Sonora, después a Nogales, viajó a El Paso, Texas y terminó sus días en Clifton, Arizona (Domecq, 1992; Vanderwood, 1998). El Niño Fidencio nació en 1898 en Yuriria, Michoacán y vivió en Iramuco, Guanajuato, desde donde se desplazó para trabajar como peón en haciendas de Michoacán y Yucatán, varios años fue cocinero en un barco y, finalmente, en 1923, llegó a la hacienda de Espinazo, en la frontera entre Nuevo León y Coahuila, donde vivió hasta su muerte (Berlanga, 1992; Monsiváis, 1992). Jesús Malverde, cuya fecha de nacimiento podría ser 1870, pudo haber nacido en Jalisco, pero se le identifica con Mocorito, cerca de la ciudad de Culiacán, por cuyos alrededores se movía de manera incesante en su calidad de asaltante de caminos (Lizárraga, 1998). Se ha dicho también que podría haber sido trabajador de la construcción o del ferrocarril que extendía sus vías en el norte de México (Quiñónez, 2001). Juan Soldado era, efectivamente, un soldado raso nacido en 1914 en Ixtaltepec, en el Istmo de Tehuantepec, Oaxaca, que fue a parar, como tal, al cuartel de un regimiento que estaba asentado en Tijuana (Valenzuela, 1992; Vanderwood, 2004).

Así las cosas, sólo dos de ellos -la Santa de Cabora y probablemente Jesús Malverde- eran propiamente oriundos del norte del país. El Niño Fidencio y Juan Soldado, en cambio, eran migrantes originarios del centro-occidente y del sur de México, por lo que es posible suponer que habían sido socializados en una matriz católica vigorosa, antigua y tradicional. De cualquier modo, los cuatro representan y, al mismo tiempo, estuvieron confrontados a la diversidad de orígenes y de experiencias religiosas que habían empezado a confluir en la frontera.

Todos murieron antes de cumplir 40 años -lo cual no era raro en ese tiempo- aunque de diferente manera. La Santa de Cabora murió a los 33 de muerte natural; el Niño Fidencio a los 40, de muerte natural anunciada por él mismo; Jesús Malverde a los 39, a raíz de las heridas mortales que le provocó un enfren- 
tamiento con una acordada; Juan Soldado a los 24 cuando fue ejecutado mediante la aplicación de la Ley Fuga.

Todos eran de origen rural -lo cual tampoco era extraño en ese tiempo-y de estrato socioeconómico bajo, salvo la Santa de Cabora que pertenecía, aunque por línea bastarda (era hija ilegítima), a la burguesía rural regional (Domecq, 1992). Sus vidas fueron difíciles, pero tampoco tan inusuales en ese tiempo y contexto. Podría decirse incluso que eso mismo suscitaba empatía y simpatía con sus adeptos. La Santa era hija de una mujer indígena, en principio ilegítima, aunque más tarde fue reconocida por su padre; el Niño Fidencio, a los 6 años, fue prestado o regalado por sus padres a una familia que, de acuerdo con Monsiváis, lo utilizó de «modo cruel y explotador» (1992: 93) y siempre padeció la crueldad de sus protectores (Riley, 1996); los padres de Jesús Malverde habrían muerto de hambre "víctimas de la explotación de los hacendados terratenientes» (Lizárraga, 1998). De Juan Soldado no se sabe nada de su vida previa a su detención y muerte en Tijuana.

En general, se trata de personajes célibes que no tuvieron descendencia. Su sexualidad, incluso, era neutra, ambigua o borrosa. La noción de niño, que se aplicó al Niño Fidencio y a la Santa de Cabora, sugieren esa condición asexuada, la inocencia de ambos en ese sentido. El Niño Fidencio, dice Monsiváis, era «un joven de muy malos recursos físicos, muy afeminado» (1992: 93). De hecho, vivió siempre como hijo adoptivo del hijo de la viuda a la que fue regalado o prestado (Berlanga et al., 1999; Riley, 1996). La Santa de Cabora fue soltera y se ha mencionado que podría haber sido violada. Ella vivió la mayor parte de su vida con su padre (Domecq, 1992; Vanderwwod, 1998). Aunque podrían representar exactamente lo contrario - un bandido- no se sabe nada al respecto acerca de Jesús Malverde. De Juan Soldado sólo se sabe que vivía con una mujer en Tijuana (Vanderwood, 2004).

Desde luego, la popularidad de los cuatro personajes tiene mucho que ver con la salud. La necesidad de ser curado de un sinfín de males del alma y del cuerpo eran fundamentales para esas sociedades aisladas y pobres, donde abundaban trabajadores y migrantes, sometidos a mil rigores, lo que hizo prosperar y extenderse la fama de los curanderos fronterizos cuyas recetas eran fáciles de seguir y conseguir y que, por lo regular, cobraban poco, en ocasiones nada por sus servicios (Malagamba, 1992; Riley, 1996). Más bien recibían y aceptaban la infinidad de regalos que les ofrecían sus devotos.

La Santa de Cabora y el Niño Fidencio vivieron y fueron ampliamente conocidos en Chihuahua, Coahuila, Nuevo León, Sonora, las entidades fronterizas más relacionadas con el estado de Texas, es decir, con el asentamiento más antiguo de trabajadores mexicanos y de los primeros migrantes. Jesús Marverde y Juan Soldado, en cambio, cobraron fama en los estados -Baja California, Sinaloa- asociados a la migración mexicana más tardía y orientada hacia California. 
La Santa de Cabora y el Niño Fidencio se consideraban mediadores eficaces entre los hombres y la divinidad. La misma asociación se hizo con Juan Soldado. No obstante su popularidad y la evocación, implícita y explícita, de elementos religiosos católicos, la iglesia rechazó, siempre, cualquier relación con ellos.

En general, vivieron en lugares aislados pero a los cuales se podía llegar por vía férrea. De hecho, el ferrocarril estuvo muy presente en la vida y la construcción de la trayectoria milagrosa de los cuatro personajes.

\section{LOS TAUMATURGOS VIVOS}

Teresa de Urrea se inició como taumaturga, es decir, como curandera milagrosa, a partir de su relación con una vieja curandera, Huila, que estaba a cargo de la casa de los Urrea. Con ella aprendió el uso de yerbas medicinales, ungüentos, emulsiones y limpias. Muy pronto, la alumna superó a su maestra (Vanderwood, 1998).

Su fase de curandera tradicional concluyó después de sufrir una serie de convulsiones que casi la mataron. Cuando mejoraba entraba en profundos periodos de trance y hablaba con la voz de una niña de cuatro años. Se dice que tuvo revelaciones divinas y recibió su misión de parte de la Virgen María. En esos días Huila, su maestra y amiga, murió sin que ella pudiera hacer nada por curarla (Vanderwood, 1998).

La muerte de Huila dio pie a la creciente fama de Teresa como curandera, vidente y taumaturga y al pueblo de Cabora como lugar de peregrinación. En 1890 ya lucía transformado por la romería de visitantes que llegaban de lugares cercanos y remotos. Muy pronto, la prensa se interesó por Teresa y empezaron a indagar acerca de sus milagros y curaciones fantásticas así como por su pasado, sus amores, su enfermedad, sus periodos de trance y sus seguidores (Vanderwood, 1998).

En las actuaciones de la Santa de Cabora se manifestaban tres grandes influencias: la cultura religiosa católica, los conocimientos teórico-prácticos del curanderismo de la zona noroeste $y$, finalmente, el espiritismo, que estaba en apogeo a fines del siglo XIX. Los seguidores de esa corriente se interesaron en la Santa, la protegían y la consideraban una verdadera médium.

Al mismo tiempo, dice Vanderwood (1998) la Santa consideraba como sus tres principales enemigos a los curas, el dinero y los doctores. La iglesia, en especial los curas de pueblo le habían declarado la guerra y en una ocasión el obispo pretendió excolmulgarla. Por otra parte, la Santa que vivía modestamente y no cobraba por sus curaciones, consideraba al dinero como una fuente de corrupción, de disolución de las familias y como causa de la pobreza en la que estaban sumidos los indios de la zona, los yaquis y mayos que la consideraban su líder espiritual. Finalmente, se enfrentaba con los doctores, que representaban en cierto modo la competencia. Aunque hay que decir también que éstos eran muy pocos y se ubicaban más bien en los centros mineros. Pero sobre todo, para ella la medicina oficial representaba a la ciencia y se contraponía con los planteamientos espiritistas de varios de sus protectores y colaboradores. 
La Santa de Cabora no era un fenómeno aislado, pero sí excepcional. De hecho, coexistía con una variedad de santos, santas y chamanes que predicaban el fin del mundo y la salvación. Pero sin duda, ella era la de mayor fama e influencia y hacia Cabora confluía una romería incesante de fieles, enfermos, curiosos y reporteros. La transmisión oral expandía su fama a nivel regional; la prensa nacional y extranjera se encargaba de proyectarla en todo México y a nivel internacional. Sus fotografías, siempre muy arregladas, circulaban en diversos formatos; se vendían estampas impresas y escapularios con su foto. La prensa, que publicaba artículos a favor y en contra de ella, también difundía su imagen.

En México se ocupaban del caso el influyente periódico El Monitor Republicano, el Diario del Hogar, La Voz de México y El Tiempo de la Ciudad de México; El Farral, El Correo y El Siglo Xx de Chihuahua; El Imparcial de Guaymas y la publicación mensual La Ilustración Espírita publicado en la Ciudad de México y Guadalajara. En el ámbito internacional se publicaban notas sobre la Santa en el Arizona Daily Star, el San Francisco Examiner, el San Francisco Call, The Cooper Era, The Clifton Arizona, e incluso el The New York Times y The New York Journal (Vanderwood, 2004).

En muchos casos, periódicos como El Diario y El Informador, de Guadalajara, retomaban las notas de otros diarios, pero varios periódicos, nacionales e internacionales, enviaron a sus reporteros hasta Cabora a hacer entrevistas y estar en el lugar de los hechos, incluso algunos hacían la prueba para ver si los sanaba de algún achaque. El acucioso y profesional trabajo de Vanderwood (1998) sobre la Santa de Cabora hace referencia a más de cincuenta periódicos que de una u otra forma hablaban de ella.

No obstante, fueron las complicaciones políticas y las revueltas armadas en las que se vio envuelta Teresa de Urrea, lo que le dio fama nacional e internacional. Si bien ella no buscaba ni pretendía participar en política, tres rebeliones locales en contra de las autoridades regionales, los militares y la dictadura usaron su nombre como bandera de lucha: los indios mayos que asaltaron Navojoa al grito de iViva la Santa de Cabora!; los yaquis la retomaron en su guerra larga y sorda contra el gobierno de Porfirio Díaz y, finalmente, los rebeldes de Tomochic, Chihuahua, fueron a visitarla y, de paso, se enfrentaron y vencieron a una partida del ejército que pretendía capturarlos (Vanderwood, 1998).

Esa fue la gota de agua que derramó el vaso. La Santa y su padre fueron aprehendidos en Cabora, trasladados a Guaymas y se les dio la posibilidad de escoger entre el exilio o la cárcel. Llegaron a Nogales donde el periodista y espiritista Lauro Aguirre se encargó de protegerlos y acomodarlos. Aguirre diseñó una campaña publicitaria para conseguir recursos y mejorar la imagen de la Santa. Desde entonces, la Niña de Cabora se convirtió en una mujer elegante, bien vestida e impecablemente peinada. Atrás quedaron el rebozo, el pelo largo y sus pertinaces seguidores, indios pobres, perseguidos por el régimen y refugiados al otro lado de la frontera (Domeq, 1992). 
Instalada en El Paso, la Santa inició una nueva etapa de su vida. Lauro Aguirre la relacionó con diversos círculos sociales, propagó sus milagrosas curaciones y la convirtió en líder espiritual de un amplio movimiento político en contra de la dictadura. La Santa se movía con soltura por las ciudades fronterizas, incluso viajó a Los Ángeles y Nueva York. Finalmente, se naturalizó norteamericana para evitar la extradición y desarrollaba con éxito sus labores curanderiles y religiosas.

No obstante, su influencia seguía viva en el México porfiriano, cada día más propenso a la revuelta que llevó finalmente a la revolución, que ella ya no tuvo oportunidad de presenciar. La Santa murió en 1906, a la evocadora edad de 33 años. Se desconoce el lugar de su tumba, pero un periodista que la ha buscado profusamente afirma haber olido, olfateado o sentido un aroma especial en el Ward's Canyon Cementery de Clifton, Arizona. Su recuerdo persiste y el pueblo de Clifton se prepara para recuperar su imagen en función de un nuevo programa turístico (Vanderwood, 1998).

El Niño Fidencio comenzó a hacerse conocido muchos años después de la Santa de Cabora. Ya habían transcurrido la revolución y la década 1910-1920; eran los tiempos de la post-revolución y la persecución religiosa. Aunque desde pequeño dio muestras de ser vidente, fue hacia 1925, cuando el Niño Fidencio, instalado como peón en la hacienda El Espinazo, empezó a curar ovejas, a recetar, secretamente, a las familias del rancho «infusiones con hierbas de la región» y a atender partos. Todo había comenzado, dice Laura Riley cuando El Niño, en una ocasión en que fue corrido de la hacienda, después de llorar mucho oyó una voz que le dijo: "Fidencio no llores, que vas a recibir el don que mi padre celestial te ha dado, tú serás el doctor de los doctores y todas las enfermedades que mi padre ha mandado tú las curarás con puras hierbitas del campo que a ti te gusten, las cocerás y esa será la medicina para todas las enfermedades» (Riley, 1996: 6). Desde entonces, el Niño estaba convencido de que curaba por mandato divino.

Cuando se hizo realmente conocido fue cuando curó a los mineros mutilados por un accidente de trabajo en la mina (Berlanga et al., 1992; Riley, 1996). En 1927 logró sanar de un dolor al dueño de la Hacienda que le prometió «regalar (le) una propaganda en todo el mundo (para) que sepan lo que tú eres» (Berlanga et al., 1992; Riley, 1996:21). Para ello mandó sacarle una fotografía que reprodujo y distribuyó por miles. Ahí nació también la afición del Niño por ser fotografiado y por preparar de manera cuidadosa las escenas y poses cuando era retratado (Riley, 1996).

El Niño también era espiritista, al parecer por influencia del dueño de la hacienda. Pero era sobre todo un curandero milagroso y tenía poderes adivinatorios. El Niño operaba con pedazos de vidrio, extraía muelas, hacía amputaciones, daba masajes, tomaba el pulso; en sus curaciones recurría a brebajes, pomadas «cánticos, oraciones y rituales» (Riley, 1996), usaba la herbolaria y, para las enfermedades de los nervios daba golpes y sustos a sus pacientes (Berlanga et al., 1999; Riley, 1996). El Niño, ya famoso, daba todos los días la bendición a los presentes en El Espinazo, ofrecía café, empezaba a curar y a dar de comer a los enfermos; en la 
noche, después de cenar reiniciaba las curaciones hasta las 6.00 de la mañana (Berlanga et al., 1992). Aunque mantenía una relación muy ambigua con las mujeres, siempre estaba rodeado de ellas (Berlanga et al., 1992).

En poco tiempo, la estación del ferrocarril se llenó de puestos de comida para los miles de peregrinos que acudían a El Espinazo en busca de curación. Ese inhóspito lugar, dice Riley, dejó de ser «un pedazo olvidado de tierra pobre y estéril (para) convertirse en «La Meca de los dolientes» (Riley, 1996:11), en verdad, había crecido una ciudad en torno al culto al Niño (Riley, 1996). Un árbol de pirul, muy cerca de la estación de ferrocarril donde el Niño recibió una revelación, se convirtió en lugar santo, siempre lleno de exvotos y ofrendas (Riley, 1996), ritual que persiste hasta la actualidad (Berlanga et al., 1999).

En 1928, a la estación de ferrocarril con que contaba la hacienda, llegaban «los vagones abarrotados de personas enfermas... a quienes... no les importaba pasar penurias en aquel desértico Espinazo en donde se encontraba el Niño Fidencio» (Berlanga et al., 1999). Ese mismo año fue la consagración definitiva. En medio del conflicto religioso más grave con la iglesia católica llegó a visitarlo, también en tren, el presidente Plutarco Elías Calles, lo que catapultó aún más la fama del Niño Fidencio.

De acuerdo con Berlanga et al. (1999) el Niño impartía sacramentos y, en vida, empezó a tener fama como santo y él mismo se sentía santo. La fama del Niño se extendía a los indios norteamericanos que acudían a visitarlo. En el sur de Texas, en especial, acumuló infinidad de seguidores.

El Niño recibió, durante años, la atención de la prensa escrita y, sobre todo, fue muy fotografiado. Le gustaba ser retratado en traje de montar o con «una cruz o con los ropajes de la Virgen de Guadalupe», pero también con los pacientes a los que curaba (Riley, 1996). En la prensa se hablaba en contra y a favor de él. Las notas y fotografías del Niño se reproducían, de manera incesante, en periódicos de diferentes lugares de la república. Fue, dice Monsiváis, un «ídolo de multitudes» (1992: 95).

Cinco años después de la muerte del Niño en 1938, comenzó a celebrarse su fiesta, el 17 de octubre, fecha que corresponde a su natalicio, celebración que ya se le hacía en vida y que es la que persiste hasta la actualidad (Riley, 1996). La devoción al Niño, siempre rechazada por la iglesia católica, se sigue trasmitiendo de generación en generación en poblaciones del noreste y centro de México y en Texas (Berlanga et al., 1992). Así, cada octubre, dice Laura Riley (1996) Espinazo se convierte «en un campo de cuerpos dolientes», de peregrinos en busca de curación.

\section{LOS TRASGRESORES MUERTOS}

En los mismos años de la Santa de Cabora, pero en el noroeste de la geografía fronteriza, vivió y murió Jesús Malverde, cuya fama de milagroso comenzó des- 
pués de su muerte y se hizo realmente popular décadas más tarde. La figura de Jesús Malverde evoca, dice Lizárraga (1998), la de Heraclio Bernal, bandolero social sinaloense asesinado en la época del porfiriato, entre otras muchas: Jesús Arriaga (Chucho el Roto), Santañón (Vanderwood, 2004). Así, Malverde es el prototipo del bandolero social que, desde muy joven y durante años, se dedicó a robar a los ricos de los alrededores de Culiacán, para ayudar a los pobres, a los desposeídos. La tradición popular cuenta que en una ocasión fue herido en una mano y la policía empezó a buscar a una persona que estuviera vendada. A los pocos días, muchos hombres se paseaban por las calles con la mano vendada como una manera de proteger la fuga del bandolero.

Se supone que murió en 1909, todavía durante el porfiriato. El gobernador prohibió que fuera incinerado o sepultado en el cementerio por lo cual su cadáver permaneció tirado en el lugar donde había muerto (Vanderwood, 2004). La gente, ante el cadáver en descomposición, comenzó a poner piedras que muy pronto se convirtieron en un montículo asociado a una flamante devoción (Vanderwood, 2004). Otras versiones señalan que el cadáver permaneció colgado de un mezquite porque nadie se atrevía a bajarlo por miedo al gobernador (Lizárraga, 1998). Finalmente, después de un tiempo «un arriero que pasaba por el lugar lo hizo y sepultó los restos mortales, no sin antes pedirle a su espíritu que le permitiera encontrar unas mulas que tenía perdidas. Las encontró y este fue quien comenzó a difundir el culto» (Lizárraga, 1998).

Los restos de Malverde, indicados por una cruz, estuvieron durante muchos años «enterrados en el monte, cerca de la estación del ferrocarril» (Lizárraga, 1998). Mujeres de la «vida galante», estibadores y cargadores de la estación del tren, que quedaba cerca comenzaron a llevarle veladoras pero también «piedras traídas ex profeso de sus lugares de origen» (Lizárraga, 1998). La urbanización de la zona, en la década de 1970, llevó a la destrucción de la tumba de Malverde lo que contribuyó a que se hablara más de él, hubiera protestas y plantones e incluso accidentes en las máquinas y a los trabajadores de la obra. La protesta atrajo la atención de la prensa y se asoció a la Operación Cóndor, que en ese mismo tiempo asolaba el campo sinaloense en busca de marihuana y opio (Vanderwood, 2004). Los restos fueron trasladados a un estacionamiento, allí se construyó una capilla donde, se supone, permanecen hasta la fecha.

En principio, se trataba de un culto muy local asociado a transgresores y trabajadores pobres y de milagros asociados a solicitudes tradicionales: la curación de enfermedades, la obtención de buenas cosechas con una forma peculiar de solicitar el milagro: había que llevarle una piedra al pedir el favor y tomar una -en calidad de amuleto- de las que estaban en la capilla hasta que se cumpliera el milagro. En ese momento, se devolvía la piedra junto con «flores, música o veladoras» (Vanderwood, 2004).

Con los años, Jesús Malverde se especializó y afirmó como imagen protectora y milagrosa de migrantes potenciales a Estados Unidos, delincuentes y de nar- 
cotraficantes -de grande y pequeña envergadura-, que es la que lo ha hecho cada vez más popular en años recientes (Vanderwood, 2004). La devoción a Malverde está muy asociada también a sus apariciones: los que lo han visto hablan de un hombre vestido de negro y montado a caballo. Está asociada también al castigo: los que no creen en él, reniegan de su intercesión o se burlan de los adeptos sufren accidentes o les regresan los males. Malverde recupera el aspecto castigador que está muy presente en algunas imágenes tradicionales y se ha asociado cada vez más como devoción de los transgresores con formas de expresión y estéticas contestatarias: armas, música, dinero. A la capilla de Malverde no acuden peregrinaciones aunque tiene algunas fechas especiales como el día de su nacimiento y de su muerte. Más bien es visitado todos los días durante las 24 horas por gente de Sinaloa y mexicanos que viven o han estado en Estados Unidos que acude a encomendarse, pedirle y agradecerle favores (Vanderwood, 2004). También sus celebraciones son peculiares: además de quemar castillos, «música de tambora o grupos de música norteña no para de sonar en toda la noche, mientras que se consumen litros de cerveza y «quisqui» Buchanan's» (Vanderwood, 2004).

Muy diferente es la historia de Juan Soldado, que nació en 1914, es decir, en medio de la revolución de 1910 y llegó en algún momento, pero desde luego muy joven y en calidad de soldado, al regimiento que se encontraba en Tijuana. El origen de la devoción está asociada a una trama de situaciones y tensiones sociales muy complicadas en ambos lados de la frontera. En la década de 1930 la ciudad de Tijuana se convirtió en lugar de paso pero también de permanencia para muchos trabajadores deportados de Estados Unidos, sufrió el impacto económico del fin de la Ley Seca en ese país, que se hizo peor aún con el cierre del Casino Agua Caliente, que dio lugar a movilizaciones sindicales intensas (Valenzuela, 1992; Vanderwood, 2004). A raíz de la guerra cristera, la iglesia católica dejó apenas un sacerdote en Baja California, asentado en Mexicali, que acudía una vez al año a decir misa a Tijuana. En ese contexto, dice Vanderwood (2004) los católicos de la región tenían que vivir su religiosidad como podían. En Tijuana, tierra de inmigrantes, no había santos patronos ni imágenes intercesoras para solicitar ayuda y agradecer favores (Vanderwood, 2004).

Por su parte, en la zona de San Diego, California, la prensa había dado cuenta, en esos mismos años, de varios secuestros y asesinatos de niños y adultos, lo que tenía alarmada a la población fronteriza y la memoria colectiva mantenía el recuerdo del secuestro y asesinato del hijo de Charles Lindberg, dice Vanderwood (2004).

En ese ambiente social, una niña de ocho años fue violada y asesinada cuando salió a hacer unas compras y nunca regresó. Al día siguiente, la encontraron muerta. Para pedir castigo y demandar la entrega del presunto asesino, el soldado Juan Castillo Morales, diversas organizaciones sociales, en especial los sindicatos, organizaron protestas, quemaron la Comandancia Municipal y el Palacio de Gobierno que dejaron varios heridos y muertos y la preocupación de las autoridades estatales y federales (Valenzuela, 1992; Vanderwood, 2004). Así las cosas, el soldado 
Juan Castillo Morales fue inmediatamente apresado, acusado, juzgado, condenado a muerte y fusilado. Su fusilamiento fue extraño, señala Vanderwood (2004): se formó de inmediato una corte marcial, la sentencia se hizo de manera pública -algo muy inusual en México para ese tiempo-y se le aplicó la Ley Fuga, una medida ilegal, que por eso mismo se suele realizar en lugares aislados y sin público (Vanderwood, 2004). En el caso de Juan Soldado fue exactamente al revés: fue fusilado en la mañana para permitir que los fotógrafos de los periódicos tuvieran suficiente luz para hacer las fotografías y para que pudieran asistir los que quisieran ser testigos del acontecimiento (Vanderwood, 2004). Todo lo anterior se explicaría, dice el mismo Vanderwood por la necesidad de tomar medidas que permitieran restablecer la autoridad en una Tijuana revoltosa.

El caso, desde la desaparición de la niña, tuvo una amplísima difusión en ambos lados de la frontera. El recuerdo de otros casos en California estaban presentes en la mente de la gente; así como lo horroroso de la muerte de la niña, la agitación social que se desató y la manera en que Juan fue ejecutado, hicieron que la noticia se publicara, durante días, en periódicos locales y nacionales de Estados Unidos y de México (Vanderwood, 2004).

Juan Soldado fue enterrado en el cementerio donde alguien puso una cruz con su nombre y fecha. La niña, enterrada a pocos metros de Juan, había sido vengada pero al mismo tiempo a un soldado joven, lejos de su casa y su familia, se le había aplicado una muerte infame: la Ley Fuga (Vanderwood, 2004). La niña nunca recibió ofrendas y poco después fue trasladada a otro cementerio (Vanderwood, 2004). En cambio, el mismo día de la muerte de Juan comenzaron a acudir los curiosos a su tumba y poco después empezó a correr la versión de que allí salía sangre, que el ánima del soldado declaraba su inocencia y pedía que castigaran al verdadero culpable (Vanderwood, 2004). Juan Soldado, había comenzado a ser redimido por la gente de Tijuana (Valenzuela, 1992). Se decía que era inocente, que había sido el chivo expiatorio de un militar de rango superior que era el verdadero violador $y$ asesino de la niña (Valenzuela, 1992).

En la tradición católica se sabía que los que morían de manera repentina y sin miedo estaban cerca de Dios por lo cual Juan podía ser un buen intermediario con la divinidad (Vanderwood, 2004). En la memoria colectiva estaba presente la historia de Jesús Malverde y la manera en que la gente convirtió su tumba en lugar de peregrinación (Vanderwood, 2004).

Así las cosas, muy pronto comenzaron a llegar las ofrendas a nombre ya solamente de Juan Soldado: flores, piedras pequeñas. La gente además comenzó a congregarse frente a su tumba a rezar el rosario; muy pronto también, comenzó a saberse de los milagros, de los que empezaron a dar cuenta ofrendas y exvotos relacionados con la salud, el trabajo, resolución de conflictos (Vanderwood, 2004).

La colocación de piedras, que aparece en los casos de Malverde y Juan Soldado, parece ser una práctica funeraria muy vieja en los cementerios de México, pero que Vanderwood considera como «una señal de respeto por una vida bien vivida o por un sacrificio bien recibido» (Vanderwood, 2004:63) (La traducción es nuestra). 
La transformación de Juan y el inicio de la devoción sucedieron en el mismo año de su muerte. Un reportero norteamericano que visitó el cementerio de Tijuana el $1^{\circ}$ de noviembre de 1938 vio que la gente se detenía a rezar ante la tumba de Juan, al que ya consideraban inocente y víctima (Vanderwood, 2004). La devoción a Juan Soldado se asoció, cada vez más, a un fenómeno imparable: el paso de trabajadores y migrantes a Estados Unidos. En 1942, cuatro años después de la muerte de Juan Soldado, comenzó el Programa Bracero que estuvo vigente hasta 1964 y a partir de ese momento se inició la fase indocumentada de la migración México-Estados Unidos (Durand, 1994). Tijuana se convirtió, durante cinco décadas, en el principal puerto de ingreso, legal e ilegal, a Estados Unidos. La visita a la tumba de Juan Soldado o llevar un amuleto con su imagen era una forma de asegurar el buen tránsito por la línea fronteriza, de protegerse en las travesías por Estados Unidos, de conseguir un buen trabajo en el otro lado, de regresar, sano y salvo, algún día a México (Durand y Massey, 2001).

Con los años, la devoción a Juan Soldado se ha extendido hacia California, lugar de destino, temporal o definitivo, de muchos migrantes, pero también hacia el resto de Baja California y Sonora donde se han construido pequeñas capillas de agradecimiento por favores recibidos (Vanderwood, 2004). Pero también, en su tumba de Tijuana, ha comenzado a recibir ofrendas y agradecimientos de gente de Oaxaca, Veracruz y la Ciudad de México (Vanderwood, 2004), lo cual ratifica su fuerte asociación con la migración, en este caso, con los migrantes de nuevas regiones mexicanas a Estados Unidos.

\section{ALGUNAS REFLEXIONES}

La saga de nuevas devociones fronterizas concluyó en la década de 1930-1940, con las muertes del Niño Fidencio y de Juan Soldado en 1938. En general, la iglesia católica, ni antes ni ahora, ha aceptado relación alguna con los personajes en cuestión; menos aún que sean santos, imágenes de culto y devoción. Su transformación en imágenes de culto y devoción ha dado lugar a muchas interpretaciones asociadas a la construcción del nuevo mundo fronterizo entre México y Estados Unidos entre 1850 y 1940. Autores como Berlanga et al., 1999; Domecq, 1992; Lizárraga, 1998; Monsiváis, 1992; Valenzuela, 1992; Vanderwod, 2004; han resaltado varios elementos.

Se ha destacado que todos surgieron y se popularizaron asociados a momentos y situaciones de grave tensión social que habían dado lugar a intensos movimientos sociales: la Santa de Cabora y Jesús Malverde vivieron y sufrieron los peores años del porfiriato; el Niño Fidencio y Juan Soldado estuvieron expuestos a la persecución religiosa, la guerra cristera. Se ha insistido bastante en la separación y el aislamiento de los pequeños asentamientos que existían en la frontera, así como en la diversidad étnico-cultural y la movilidad laboral de sus 
poblaciones. La nueva frontera, el ferrocarril, la integración con Estados Unidos generaban flujos -antiguos y nuevos- de gente que tenía que aprender, no sin conflicto, a coexistir y convivir. La heterogeneidad social, los encuentros con la diferencia, la distancia con los lugares de origen tendían a diluir los lazos de la iglesia católica con su feligresía.

Al mismo tiempo, la propia iglesia católica tenía muy desatendida su grey fronteriza y la región carecía de santos patronos e imágenes intercesoras que tanto existían en el resto de México. Todo ello, convertía a la frontera en un caldo de cultivo apto para el surgimiento de devociones con referentes que incorporaban las condiciones sociales de tensión social, de pobreza, exclusión, marginación, injusticia, arbitrariedad, discriminación, inseguridad ante la sociedad y la naturaleza en las que transcurría la vida de muchos de los viejos y nuevos pobladores de la frontera.

Allí, además de la ausencia, la separación, las deportaciones, los cambios laborales, la tristeza, el azoro, proliferaban las infinitas enfermedades del cuerpo para las cuales existía poca atención profesional, escasísimos recursos terapéuticos. No es de extrañar que la Santa de Cabora y el Niño Fidencio fueran conocidos, en principio, por sus dotes como curanderos de todo tipo de males así como por el hecho de que no cobraban por sus servicios. No es de extrañar tampoco la aparición e identificación de la gente con figuras como Malverde y Juan Soldado que en el imaginario colectivo evocaban a los bandidos sociales, a las víctimas de la arbitrariedad y la injusticia, al sacrificio de los pobres.

Los agradecidos, los que eran beneficiarios de curaciones y alcanzados por los milagros recurrieron a su arsenal de recursos antiguos y probados para dar a conocer su gratitud: conversión de los lugares de curación y culto en santuarios, peregrinaciones, procesiones, asociación y celebración de una o dos fechas significativas al año que catapultaban y calendarizaban las peregrinaciones, la colocación de piedras, la dotación de abundantes y ejemplares exvotos, los relatos infinitos de curaciones asombrosas y sucesos milagrosos, eventualmente, también de castigos por la falta de cumplimiento de una promesa, elementos que se incorporaban a la tradición oral que circulaba por ranchos cercanos y lejanos ante oídos ávidos de noticias y novedades del mundo.

Los personajes mismos apelaban a ese transfondo de saberes religiosos compartidos que remitían sin duda a enseñanzas y ejemplos de la Biblia: la Santa de Cabora curaba con saliva y tierra, se retiraba a orar y repetía frases que recordaban a Jesucristo; el Niño Fidencio curaba con agua, tocaba a los enfermos y también se retiraba a orar. La gente, heredera de una añosa tradición católica, conocía, reconocía pero también sabía utilizar esos recursos, viejos pero eficaces, para generar cultos y desencadenar devociones hacia otros y hacia ellos mismos.

Pero no todo era mirar hacia atrás. La construcción de devociones en la frontera integró elementos novedosos que tenían que ver con la complejidad y diversidad social y el momento histórico, en especial, con la marginalidad y la trans- 
gresión. Los cuatro personajes eran sin duda transgresores en varios sentidos: la Santa de Cabora, además de ser mujer en un mundo regido por hombres, se convirtió, queriéndolo o no, en la líder de movimientos milenaristas como el de Tomochic, en Chihuahua; el Niño Fidencio era un personaje afeminado que gozaba de plena aceptación entre hombres y mujeres; Malverde era un bandido social legitimado y Juan Soldado un violador y asesino convertido en víctima. Al mismo tiempo, capturaban sus principales adeptos entre marginales y transgresores que en esas nuevas imágenes y devociones redescubrían la posibilidad de la inclusión: indígenas, participantes en movimientos sociales, pobres, mujeres, enfermos, bandidos, prostitutas, migrantes, delincuentes, narcotraficantes.

Así las cosas, en la frontera se recreó, con personajes contemporáneos, vivos y muertos, una práctica religiosa que recuperó las transiciones, fenómenos sociales y poblaciones de la frontera para las cuales ya no era suficiente ni convincente el aparicionismo ni la recreación de imágenes santas, tan socorridas y frecuentes en el resto de México hasta fines del siglo XIx para generar y difundir hitos, espacios, ritos y mitos sagrados. En la frontera, la espacialidad religiosa, de este a oeste, fue copada por personajes que se separaron de los mitos originarios y se transformaron, como diría Alicia Barabás (en prensa), en «textos libres» donde se recrearon los recursos de la religiosidad antigua con los fenómenos emergentes y urgentes de una frontera en construcción asociada a nuevos pobladores portadores de distintas tradiciones religiosas así como de tensiones y movimientos sociales, migración e incertidumbre, tradición y transgresión.

Pero habría que destacar algo más. Se ha insistido mucho en que las poblaciones fronterizas estaban aisladas. Pero quizá sería más correcto decir que eran pequeñas y estaban dispersas y separadas unas de otras pero quizá no tan aisladas del resto del mundo, ni tan al margen de lo que sucedía en otros lugares como se suele pensar. La aparición y popularización de esas devociones en la frontera parece estar asociada, por una parte, a los procesos de secularización y cambio religioso; por otra, a los desarrollos tecnológicos en relación a la comunicación de personas y noticias. Pero se trataba de una secularización que requería, todavía, de importantes expresiones públicas (Mallimaci, 2004).

La santificación de personas vivas y muertas no sólo al margen sino abiertamente en contra de la iglesia da cuenta de un sincretismo asociado a amplio rechazo al catolicismo tradicional y a sus representantes, es decir, fueron devociones emanadas de una legimitidad contestaria, enfrentada con el poder de la iglesia. Una de ellas fue la asociación con el espiritismo. La Santa de Cabora y el Niño Fidencio incorporaron muchos elementos de ese movimiento que llegó a México a mediados del siglo XIX y muy pronto sumó adeptos en diversas regiones y diferentes grupos sociales (Vanderwwod, 1998). La Santa y el Niño mantenían relaciones muy cercanas con personas estrechamente vinculadas al espiritismo. La cercanía con ese movimiento les dio, a ambos, amplia difusión nacional e inter- 
nacional entre sus seguidores que contaban con redes de comunicación y publicaciones especializadas.

La corte y el ritual que acompañaban a la Santa de Cabora y al Niño Fidencio recuerdan a los movimientos milenaristas que aparecieron a fines del siglo XIX en diversas partes del mundo, vinculados, algunos, a movimientos políticos; otros, a santones de tipo más bien «candoroso» (Monsiváis, 1992).

Finalmente, la difusión y popularización de esos cuatro personajes estuvo íntimamente relacionada con tres grandes avances tecnológicos de la época: el ferrocarril, la prensa y la fotografía. La movilidad de los personajes en cuestión, pero en especial de sus adeptos, fue posible gracias a las flamantes comunicaciones que estrenó el ferrocarril. Por esa vía llegaron al norte el Niño Fidencio y Juan Soldado; por esa vía, se desplazó en sus exilios la Santa de Cabora. Pero el ferrocarril hizo posible, sobre todo, los viajes y peregrinaciones de la gente, hombres, mujeres y niños, a conocerlos, honrarlos y de ese modo tener la experiencia de estar con ellos, de repetirla si era posible, de difundirla lo más posible. El tren vinculaba los asentamientos dispersos, reunía gente, amalgamaba saberes y generaba nuevas experiencias y querencias religiosas. La posibilidad de viajar en tren contribuyó, sin duda, a hacer accesible y expandir la devoción a la Santa de Cabora y el Niño Fidencio. La tradición oral, desde entonces, comenzó a movilizarse en tren, ya no sólo en boca de viajeros ocasionales y arrieros profesionales.

Pero quizá no hubiera sido suficiente. Los personajes en cuestión disfrutaron, todos, de muy buena y abundante prensa, en ambos lados de la frontera y en todo México. En ese tiempo, los periódicos estatales recogían notas de la prensa nacional y las reproducían localmente por lo cual era posible seguir personajes, noticias y acontecimientos en lugares muy distantes de la frontera. De ese modo, todo el mundo pudo seguir de cerca, en ocasiones de manera cotidiana, las travesías y peripecias de la Santa de Cabora en uno y otro lado de la frontera; el suceso, que la prensa hizo inolvidable, de la visita del presidente de la república al Niño Fidencio en pleno conflicto cristero; las protestas por el intento de destruir la tumba de Jesús Malverde; la muerte de la niña en Tijuana, las protestas, el juicio y asesinato de Juan Soldado. No sólo eso. Las noticias, ya en ese momento, se acompañaban de fotografías de lo que sucedía con cada uno de ellos y en sus santuarios. Desde entonces, mucha gente podía seguir los sucesos y, además, verlos, reconocerlos, establecer sus propios juicios acerca de ellos. Juan Soldado fue profusamente retratado sólo para morir.

Las fotografías no eran sólo noticias. Había además fotos posadas que se vendían de múltiples maneras y en muy distintos lugares. La Santa y El Niño se volvieron adictos a la fotografía, a la construcción fotográfica de sus imágenes. Así las cosas puede decirse que la fama que alcanzaron y la devoción que generaron la Santa de Cabora, el Niño Fidencio, Jesús Malverde y Juan Soldado estuvo indisolublemente ligada a esos recursos tecnológicos a los que estuvieron expuestos pero de los cuales ellos y sus seguidores aprendieron a sacar ventaja. Los avances 
tecnológicos de fines del siglo XIX se convirtieron en los cómplices modernos del muy viejo y socorrido recurso de la tradición oral para difundir imágenes de culto y popularizar milagros que rediseñaron la geografía religiosa mexicana.

\section{BIBLIOGRAFÍA}

AnAYA, José Vicente (1992), «Mitos de los caras pálidas sobre los apaches», en José Manuel Valenzuela Arce (compilador), Entre la magia y la historia. Tradiciones, mitos y leyendas de la frontera, México, Programa Cultural de las Fronteras-El Colegio de la Frontera Norte, pp. 33-47.

ArIAs, Patricia (2004), «Exvotos y espacialidad en el siglo XIX. La apropiación social de una práctica misionera», en Miguel Hernández Madrid y Elizabeth Juárez Cerdí (coordinadores), Religión y cultura, Zamora, El Colegio de Michoacán, pp. 89-106.

Barabás, Alicia (En prensa), "Los santuarios de vírgenes y santos aparecidos en Oaxaca», Estudios del Hombre, Guadalajara, Universidad de Guadalajara-CUCSH.

BerLanGa, José Luis, Eric Lara y César Ramírez (1999), Las fiestas del dolor: un estudio sobre las celebraciones del Niño Fidencio, Monterrey, Gobierno del Estado de Nuevo LeónFondo Estatal para la Cultura y las Artes de Nuevo León.

Domeco, Brianda (1990), La insólita historia de la Santa de Cabora, México, Editorial Planeta. (1992), "Un collage (sobre la Santa de Cabora)», en José Manuel Valenzuela Arce (compilador), Entre la magia y la historia. Tradiciones, mitos y leyendas de la frontera, México, Programa Cultural de las Fronteras-El Colegio de la Frontera Norte, pp. 51-61.

Durand, Jorge (1994), Más allá de la línea. Patrones migratorios entre México y Estados Unidos, México, Conaculta.

y Douglas S. Massey (2001), Milagros en la frontera. Retablos de inmigrantes mexicanos a Estados Unidos, México, El Colegio de San Luis-CIESAS.

y Patricia Arias (2005), La vida en el norte. Historia e iconografía de la migración México-Estados Unidos, Guadalajara, Universidad de Guadalajara.

GaXiola, Manuel J. (1994), La serpiente y la paloma: Historia, teología y análisis de la Iglesia Apostólica de la Fe en Cristo Jesús (1914-1994), México, Libros Pyros.

Hernández Hernández, Alberto (1999), «La formación de la frontera norte y el protestantismo», en Patricia Galeana (coordinadora), Nuestra frontera norte, México, Archivo General de la Nación, pp. 61-79.

Lizárraga Hernández, Arturo (1998), "Jesús Malverde: Ángel de los pobres», Revista de la Universidad Autónoma de Sinaloa, núm.1, Culiacán, pp. 51-57.

Malagamba, Amelia (1992), "Don Pedrito Jaramillo, una leyenda mexicana en el sur de Texas», en José Manuel Valenzuela Arce (compilador), Entre la magia y la historia. Tradiciones, mitos y leyendas de la frontera, México, Programa Cultural de las FronterasEl Colegio de la Frontera Norte, pp. 63-73.

Maldimaci, Fortunato (2004), "Catolicismos y liberalismo: las etapas del enfrentamiento por la definición de la modernidad religiosa en América Latina», en Jean Pierre Bastian (coordinador), La modernidad religiosa: Europa latina y América Latina en perspectiva comparada, México, FCE, pp. 19-44. 
Monsivárs, Carlos (1992), "José de Jesús Fidencio Cíntora: el niño Fidencio», en José Manuel

Valenzuela Arce (compilador), Entre la magia y la historia. Tradiciones, mitos y leyendas de la frontera, México, Programa Cultural de las Fronteras-El Colegio de la Frontera Norte, pp. 89-95.

OKTAVeC, Eileen (1995), Answered Prayers. Miracles and Milagros along the Border, Tucson, The University of Arizona Press.

Quinones, Sam (2001), True Tales from Another Mexico, Tucson, University of New Mexico Press.

Riley, Luisa (1996), «Fidencio, el Niño Fidencio», Luna Córnea, Núm. 9, pp. 5-15.

Valenzuela Arce, José Manuel (1992), «Introducción», en José Manuel Valenzuela Arce

(compilador), Entre la magia y la historia. Tradiciones, mitos y leyendas de la frontera, México, Programa Cultural de las Fronteras-El Colegio de la Frontera Norte, pp. 13-19.

(1992), «Por los milagros recibidos: religiosidad popular a través del culto a Juan Soldado", en José Manuel Valenzuela Arce (compilador), Entre la magia y la historia. Tradiciones, mitos y leyendas de la frontera, México, Programa Cultural de las FronterasEl Colegio de la Frontera Norte, pp. 75-87.

Vanderwood, Paul J. (1998), The Power of God Against the Guns of Government, Stanford, Stanford University Press.

(2004), Rapist, Murderer, Martyr, Saint, Durham and London, Duke University Press. 